\title{
Rapid deployment aortic valve replacement devices: Too many unanswered questions
}

\author{
Michael N. D'Ambra, MD
}

\footnotetext{
From the Department of Anesthesia and the Division of Cardiothoracic Surgery, University of Maryland Medical Center, Baltimore, Md.

Disclosures: Author has disclosed consulting fees from Edwards Lifescience.

Received for publication Feb 11, 2018; accepted for publication Feb 15, 2018; available ahead of print March 24 2018.

Address for reprints: Michael N. D’Ambra, MD, University of Maryland Medical Center, 22 S Greene St, Baltimore, MD 21201 (E-mail: mdambra@gmail.com).

J Thorac Cardiovasc Surg 2018;155:2413

$0022-5223 / \$ 36.00$

Copyright (c) 2018 by The American Association for Thoracic Surgery

https://doi.org/10.1016/j.jtcvs.2018.02.045
}

In this issue of the Journal, Sohn and colleagues ${ }^{1}$ have completed an extensive meta-analysis of outcome studies for rapid deployment aortic valve replacement (RDAVR) devices versus conventional aortic valve replacement. Two vendors' RDAVR products were studied, Edwards Intuity (Edwards Lifesciences, Irvine, Calif) and St Jude Sorin Perceval (St Jude Medical, St Paul, Minn). Sohn and colleagues ${ }^{1}$ found that implantation of these devices shortened the duration of cardiopulmonary bypass and cardioplegic arrest. In addition, both were associated with a significant increase in permanent pacemaker insertion.

The question, not answered in this study, arises as to the difference between pacemaker insertion rate versus longterm pacemaker dependence. Insertion rates would be expected to be increased in medical systems that optimize care for the shortest hospital length of stay (United States), as opposes to systems where longer stays do not have a major impact on medical decision making (Europe). What we do not know from the analysis of Sohn and colleagues ${ }^{1}$ are the pacemaker dependence rates.

Another data point not included in this analysis is the difference between these RDAVR devices. Because all industry-sponsored trials support the study of a single device, with or without controls and random assignment to open surgery, meta-analysis is the only way for surgeons to assess performance and outcome between competing devices such as Intuity and Perceval. Because there were not enough patients for one of the devices in this study to provide adequate power to distinguish, no comparative analysis was done for pacemaker insertion rates or for hemodynamic performance, which is especially important in the smaller valve sizes.

The durability of these devices was also not addressed. Head-to-head comparison (by meta analysis) will be smaller valve sizes.

\section{Reference}

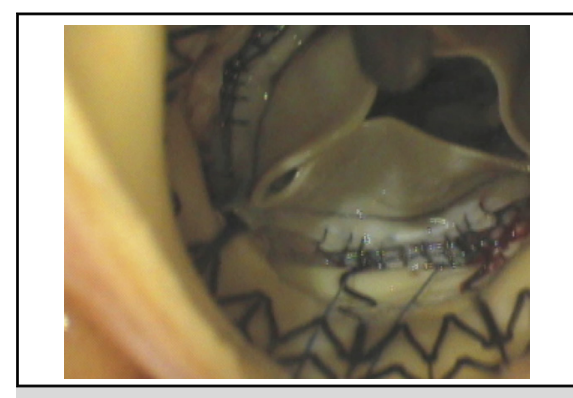

Surgical inspection of deployed rapid deployment aortic valve replacement device.

\section{Central Message}

Rapid deployment aortic valve replacement devices require much more study before definitive recommendations regarding their use can be made.

See Article page 2402 .

required to determine whether there is any durability advantage to either RDAVR device.

Few hospitals will be stocking two devices for the same application, so surgeons will be consulted by hospital administrators to choose which device they prefer. In RDAVR, surgeons are left without hard evidence to support such a recommendation, and they will continue to be dependent on information and opinion from industry colleagues. Future investigators, including industrysponsored clinical researchers, regulatory bodies, large payers, medical provider systems, and independent meta-analysts, are encouraged to pick up where Sohn and colleagues ${ }^{1}$ have left off to provide consultant surgeons with comparative analyses on heart block, durability, morbid outcomes, and hemodynamic performance in the

Regulatory bodies and large medical care systems are encouraged to make data available to researchers so that unbiased analysis can provide the facts that we all need to make proper decisions for our patients.

1. Sohn SH, Jang MJ, Hwang HY, Kim KH. Rapid deployment or sutureless versus conventional bioprosthetic aortic valve replacement: a meta-analysis. J Thorac Cardiovasc Surg. 2018;155:2402-12.e5 